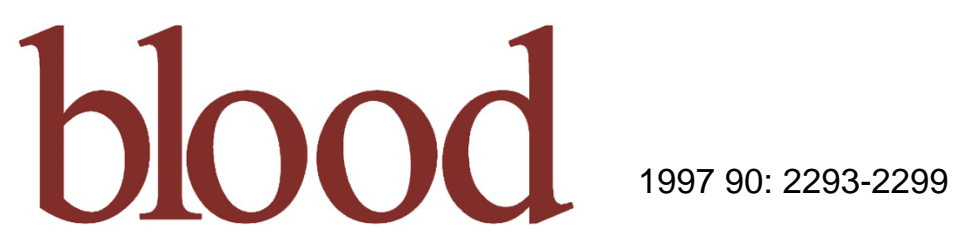

\title{
Cell Cycle Analysis and Synchronization of Pluripotent Hematopoietic Progenitor Stem Cells
}

G. Prem Veer Reddy, Cheryl Y. Tiarks, Lizhen Pang, Joanne Wuu, Chung-Cheng Hsieh and Peter J. Quesenberry

Updated information and services can be found at:

http://bloodjournal.hematologylibrary.org/cgi/content/full/90/6/2293

Articles on similar topics may be found in the following Blood collections:

Hematopoiesis (2346 articles)

Information about reproducing this article in parts or in its entirety may be found online at:

http://bloodjournal.hematologylibrary.org/misc/rights.dtl\#repub_requests

Information about ordering reprints may be found online at:

http://bloodjournal.hematologylibrary.org/misc/rights.dt|\#reprints

Information about subscriptions and ASH membership may be found online at:

http://bloodjournal.hematologylibrary.org/subscriptions/index.dtl

Blood (print ISSN 0006-4971, online ISSN 1528-0020), is published semimonthly by the American Society of Hematology, 1900 M St, NW, Suite 200, Washington DC 20036.

Copyright 2007 by The American Society of Hematology; all rights reserved.

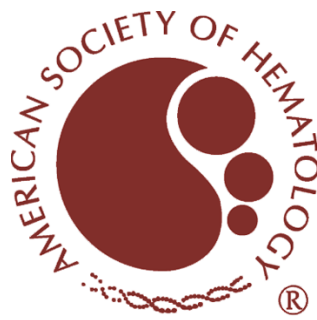




\title{
Cell Cycle Analysis and Synchronization of Pluripotent Hematopoietic Progenitor Stem Cells
}

\author{
By G. Prem Veer Reddy, Cheryl Y. Tiarks, Lizhen Pang, Joanne Wuu, Chung-Cheng Hsieh, and Peter J. Quesenberry
}

Hematopoietic stem cells purified from mouse bone marrow are quiescent with less than $2 \%$ of $\mathrm{Lin}^{-}$Hoechst ${ }^{\text {low }} /$ Rhodamine ${ }^{\text {low }}$ ( $\mathrm{Lin}^{-} \mathrm{Ho}^{\text {low }} / \mathrm{Rho}^{\text {low }}$ ) and $10 \%$ to $15 \%$ of $\mathrm{Lin}^{-} / \mathrm{Sca}^{+}$cells in $S$ phase. These cells enter proliferative cycle and progress through $G_{1}$ and into $S$ phase in the presence of cytokines and $5 \%$ heat-inactivated fetal calf serum (HI-FCS). Cytokinestimulated $\mathrm{Lin}^{-} \mathrm{Ho}^{\text {low }} / \mathrm{Rho}^{\text {low }}$ cells took 36 to 40 hours to complete first division and only 12 hours to complete each of 5 subsequent divisions. These cells require 16 to 18 hours to transit through $G_{0} / G_{1}$ period and 28 to 30 hours to enter into mid-S phase during the first cycle. Up to $56 \%$ of $\mathrm{Lin}^{-}$ $\mathrm{Rho}^{\text {low }} / \mathrm{Ho}^{\text {low }}$ cells are high-proliferative potential $(7$ factorresponsive) colony-forming cells (HPP-CFC). At isolation, HPP-CFC are quiescent, but after 28 to $\mathbf{3 0}$ hours of culture, greater than $60 \%$ are in $S$ phase. Isoleucine-deprivation of Lin $^{-} \mathrm{Ho}^{\text {low }} / \mathrm{Rho}^{\text {low }}$ cells in $\mathrm{S}$ phase of first cycle reversibly blocked them from entering into second cycle. After the release from isoleucine-block, these cells exhibited a $G_{1}$ period

$\mathbf{M}$ URINE PRIMITIVE long-term repopulating lymphohematopoietic stem cells have been characterized by the absence of differentiated lineage markers $\left(\operatorname{Lin}^{-}\right)$, the presence of cell surface Ly-6 antigen $\left(\mathrm{Sca}^{+}\right)$and c-Kit, and relatively low levels of staining with the supravital dyes rhodamine-123 and hoechst-33342. Lin $^{-}$cells expressing Sca or c-Kit or showing low staining with rhodamine $\left(\mathrm{Rho}^{\text {low }}\right)$ and hoechst $\left(\mathrm{Ho}^{\text {low }}\right)$ are relatively quiescent and enriched for multifactor-responsive high proliferative potential colony-forming cells (HPP-CFC), although using continuous bromo-deoxyuridine (BrdU) labeling, Bradford et $\mathrm{al}^{1}$ have shown that most of the $\mathrm{Lin}^{-} \mathrm{Rho}^{\text {low }} / \mathrm{Ho}^{\text {low }}$ cells have entered cell cycle over a 12 -week time interval.

The primitive long-term repopulating cells can be induced to proliferate after in vivo exposure to cytotoxic agents, such as 5-fluorouracil (5-FU) or in vitro exposure to cytokines. Particular attention has focused on the possibility of using such proliferative stimuli to expand stem cells or to facilitate retroviral integration in gene therapies. ${ }^{2-7}$ These manipulations can result in expansion and cycle activation of primitive surrogate stem cells, HPP-CFCs, but with a concomitant loss of long-term, but not short-term, in vivo engraftment potential, ${ }^{8,9}$ and through in vivo hydroxyurea suicide experiments, it was shown that the cells engrafting into nonmyeloablated marrow, spleen and thymus were insensitive to hydroxyurea and, therefore, noncycling. ${ }^{10}$ Spleen colonyforming ability of cycling cells was reported to be $50 \%$ less than that of normal marrow or velocity sedimented noncycling cells. ${ }^{11}$ Studies using purified populations of stem cells showed that $100 \mathrm{G}_{0} / \mathrm{G}_{1}$ cells are capable of protecting $90 \%$ of lethally irradiated recipients, whereas the $100 \mathrm{~S} / \mathrm{G}_{2} / \mathrm{M}$ phase cells protect only $22 \%$ of recipients. ${ }^{12}$

Although these observations show an engraftment defect in mitotically active hematopoietic progenitor/stem cells, they fail to fully establish a cause and effect relationship between the engraftment defect and the cell cycle status of stem cells induced to proliferate. To address this issue more critically, it is important that the same population of purified pluripotent hematopoietic stem cells (PHSCs) in their quies- of less than 2 hours and entered into mid-S phase by 12 hours. Thus, the duration of $G_{1}$ phase of the cells in second cycle is 4 to 5 times shorter than that observed in their first cycle. Similar cell cycle kinetics are observed with $\mathrm{Lin}^{-} / \mathrm{Sca}^{+}$ population of bone marrow cells. Stem cell factor (SCF) alone, in the presence of HI-FCS, is as effective as a cocktail of 2 to 7 cytokines in inducing quiescent $\mathrm{Lin}^{-} / \mathrm{Sca}^{+}$cells to enter into proliferative cycle. Aphidicolin treatment reversibly blocked cytokine-stimulated $\mathrm{Lin}^{-} / \mathrm{Sca}^{+}$cells at $\mathrm{G}_{1} / \mathrm{S}$ boundary, allowing their tight synchrony as they progress through first $S$ phase and enter into second $G_{1}$. For these cells also, SCF alone is sufficient for their progression through $S$ phase. These studies indicate a very short $G_{1}$ phase for stem cells induced to proliferate and offer experimental approaches to synchronize murine hematopoietic stem cells.

(C) 1997 by The American Society of Hematology.

cent state be followed for their ability to engraft at specific phases as they traverse the cell cycle after proliferative stimulation. This would require not only a fuller understanding of the kinetics of cell cycle entry and progression of cytokinestimulated quiescent PHSCs, but also developing procedures that allow synchronization and enrichment of PHSCs to represent specific phases of cell cycle after proliferative stimulation. In the present studies, we have characterized the cell cycle kinetics of $\mathrm{Lin}^{-} \mathrm{Rho}^{\text {low }} / \mathrm{Ho}^{\text {low }}$ and $\mathrm{Lin}^{-} / \mathrm{Sca}^{+}$stem cells after exposure to a 4-cytokine cocktail consisting of interleukin-3 (IL-3), IL-6, IL-11, and stem cell factor (SCF) or SCF alone and developed experimental conditions that allow their synchronization in early $\mathrm{S}$ phase of the first cycle.

\section{MATERIALS AND METHODS}

Purification of $\mathrm{Lin}^{-} / \mathrm{Sca}{ }^{+}$and $\mathrm{Lin}^{-} \mathrm{Rhol}{ }^{\text {low }} / \mathrm{Ho}^{\text {low }}$ cells from mouse bone marrow. Sorting of the $\mathrm{Lin}^{-} / \mathrm{Sca}^{+}$cells involved recovering marrow from tibiae and femora of 6- to 8-week old Balb/c or C57BLK6 mice under sterile conditions and enriching low-density cells by equilibrium density centrifugation is as described by Wolf et al. ${ }^{13}$ Low-density cells were subjected to immunomagnetic bead depletion of lineage-committed cells using a panel of antibodies against Ter 119 (erythroid), B220 (B and pre-B lymphocytes), MAC1 (macrophages), GR-1 (granulocytes), Lyt-2 (T-cells), L3T4 (Thelper cells), and YW25.12.17 (erythroid). Antibodies against B220,

From the Cancer Center and Department of Cell Biology, University of Massachusetts Medical Center, Worcester, MA.

Submitted September 19, 1996; accepted May 23, 1997.

Supported by National Institutes of Health Grants No. POIHL56920 and PO1DK-50222-01.

Address reprint requests to G. Prem Veer Reddy, PhD, Cancer Center, University of Massachusetts Medical Center, 373 Plantation St, Suite 202, Worcester, MA 01605.

The publication costs of this article were defrayed in part by page charge payment. This article must therefore be hereby marked "advertisement" in accordance with 18 U.S.C. section 1734 solely to indicate this fact.

(C) 1997 by The American Society of Hematology.

0006-4971/97/9006-0026\$3.00/0 
MAC-1, and GR-1 were also biotin-conjugated. Lineage-depleted cells were then incubated with fluorescein isothiocyanate (FITC)conjugated anti-SCA-1 antibodies (PharMingen, San Diego, CA) and phycoerythrin (PE) streptavidin (Biomeda, Foster City, CA) and sorted on FACS-STAR (Becton Dickinson, San Francisco, CA) to recover FITC-positive and PE-negative cells.

The overall procedure for sorting of $\mathrm{Lin}^{-}, \mathrm{Rho}^{\text {low }} / \mathrm{Ho}^{\text {low }}$ cells from murine bone marrow is essentially as described by Wolf et al. ${ }^{13}$ Briefly, this procedure involved recovering lineage-depleted bone marrow cells as described above and labeling them with Rhodamine123 and Hoechst-33342. The labeled cells were then sorted on FACS-STAR (Becton Dickinson) or on MoFlo (Cytomation, Fort Collins, CO) cell sorter to recover lowest 10\% Rhodamine-123 staining and lowest 3\% Hoechst-33342 staining cells.

In vitro culture and synchronization of hematopoietic progenitor/ stem cells. Immediately after their purification, $\mathrm{Lin}^{-} / \mathrm{Sca}^{+}$or $\mathrm{Lin}^{-}$, $\mathrm{Rho}^{\text {low }} / \mathrm{Ho}^{\text {low }}$ cells were incubated at a density of 10 to $20 \times 10^{3}$ cells/mL in Dulbecco's Modified Essential Medium (DMEM; GIBCO-BRL, Grand Island, NY) containing 5\% heat-inactivated fetal calf serum (HI-FCS; HyClone Laboratories, Logan, UT), glutamine $(2.5 \mathrm{mmol} / \mathrm{L})$, penicillin $(100 \mathrm{U} / \mathrm{mL})$, streptomycin $(100 \mu \mathrm{g} /$ $\mathrm{mL}$ ), and appropriate cytokines at $37^{\circ} \mathrm{C}$ in a $5 \% \mathrm{CO}_{2}$ containing humidified incubator. Unless otherwise indicated, the concentration and the source of individual cytokines added in different combinations to the media in these studies were recombinant murine SCF (mSCF) at $100 \mathrm{ng} / \mathrm{mL}$ (R\&D Systems, Minneapolis, MN), mIL-3 at $100 \mathrm{U} / \mathrm{mL}$ (Collaborative), mIL-6 at $50 \mathrm{U} / \mathrm{mL}$ (R\&D), recombinant human IL-11 (hIL-11) at $50 \mathrm{ng} / \mathrm{mL}$ (Genetics Institute, Cambridge, MA), IL- $1 \alpha$ at $250 \mathrm{U} / \mathrm{mL}$ (Hoffmann La Roche, Nutley, NJ), granulocyte-macrophage colony-stimulating factor (GM-CSF) at $2.5 \mathrm{ng} /$ $\mathrm{mL}(\mathrm{R} \& \mathrm{D})$, granulocyte colony-stimulating factor (G-CSF) at $5 \mathrm{ng} /$ $\mathrm{mL}$ (Collaborative), basic fibroblast growth factor (bFGF) at $5 \mathrm{ng} /$ $\mathrm{mL}$ (R\&D), and CSF-1 at 5,000 U/mL (Chiron, Emeryville, CA).

For synchronization of the cells at $\mathrm{G}_{1} / \mathrm{S}$ boundary, hematopoietic stem cells exposed to the medium containing a cocktail of 7 cytokines (IL-3, IL- $1 \alpha$, G-CSF, GM-CSF, SCF, CSF-1, and bFGF) described above for 8 hours were treated with $2 \mu \mathrm{g} / \mathrm{mL}$ of aphidicolin (Sigma Chemical Co, St Louis, MO) for next 24 hours. To release the cells from aphidicolin-block, they were washed once with complete medium and placed in medium containing either the cocktail of 7 cytokines or $\mathrm{mSCF}(200 \mathrm{ng} / \mathrm{mL})$ alone.

For synchronization of $\mathrm{S}$ phase $\mathrm{Lin}^{-}, \mathrm{Rho}^{\text {low }} / \mathrm{Ho}^{\text {low }}$ cells in their subsequent $\mathrm{G}_{0} / \mathrm{G}_{1}$ phase, the cells were first incubated in the presence of medium containing a cocktail of 4 cytokines (mIL-3, mIL-6, hIL11 , and $\mathrm{mSCF}$ ) for 30 hours and then washed once with isoleucinefree DMEM and incubated with isoleucine-free DMEM (GIBCOBRL) containing dialyzed HI-FCS (HyClone Laboratories), glutamine, penicillin, streptomycin, and a 4-cytokine cocktail at the concentrations indicated above. Thirty-six hours of isoleucine deprivation was found to be sufficient for reversibly blocking $\mathrm{Lin}^{-} \mathrm{Rho}^{\text {low/ }}$ $\mathrm{Ho}^{\text {low }}$ cells in $\mathrm{G}_{0} / \mathrm{G}_{1}$ phase. Cells were released from isoleucineblock by replacing isoleucine-free medium with complete medium containing the appropriate cytokines.

Autoradiographic detection of ${ }^{3} \mathrm{H}$-thymidine-labeled nuclei. The number of cells in $\mathrm{S}$ phase were determined by autoradiography of the cells after pulse labeling with ${ }^{3} \mathrm{H}$-thymidine as described elsewhere. ${ }^{14}$ Briefly, duplicate aliquots of cells $(500$ to 1,000$)$ at regular intervals as they are progressing through cell cycle were incubated with $2.5 \mu \mathrm{Ci} / \mathrm{mL}$ of ${ }^{3} \mathrm{H}$-thymidine at $37^{\circ} \mathrm{C}$ in $5 \% \mathrm{CO}_{2}$ containing humidified incubator for 30 minutes. The incorporation of ${ }^{3} \mathrm{H}$-thymidine was terminated by cytospin centrifugation and immediately fixing with methanol/acetic acid $(2: 1 \mathrm{vol} / \mathrm{vol})$, followed by three washes in methanol. Slides were allowed to air dry overnight and a thin film of Kodak nuclear track NTB3 emulsion (Eastman Kodak, Rochester, NY) was applied. Slides were then incubated in the dark for 4 days, developed, and fixed with Kodak Decktol Developer and Kodak Fixer, respectively. Slides were washed extensively and stained with Giemsa. The percentage of cells with labeled nuclei (representing cells in S phase) was assessed by counting 150 to 200 cells on each slide.

Hematopoietic progenitor cell assay. The cloning efficiency of $\mathrm{Lin}^{-} \mathrm{Rho}^{\text {low }} / \mathrm{Ho}^{\text {low }}$ cells was determined by analysis of HPP-CFC using a double-layer nutrient agar culture system essentially as described. ${ }^{15}$ One thousand cells obtained immediately after sorting or at indicated intervals after cytokine stimulation were withdrawn from the in vitro liquid culture and plated in $35-\mathrm{mm}$ petri dishes containing double-layer nutrient agar at a density of 100 cells per plate. One milliliter of underlayer in each plate contained $\alpha$-minimum essential medium ( $\alpha$-MEM) with $20 \%$ fetal calf serum supplemented with vitamins, glutamine, and 7 cytokines (IL-1, IL-3, CSF-1, GM-CSF, G-CSF, SCF, and bFGF), along with a final agar concentration of $0.5 \%$. Cells were included in $0.5 \mathrm{~mL}$ overlayer with a final agar concentration of $0.3 \%$. Culture dishes with the cells were then incubated at $37^{\circ} \mathrm{C}$ for 14 days in the presence of $5 \% \mathrm{O}_{2}, 10 \% \mathrm{CO}_{2}$, and $85 \% \mathrm{~N}_{2}$ and scored for HPP-CFC using a dissecting microscope. HPP-CFC typically generated colonies greater than $0.5 \mathrm{~mm}$ in diameter, consisting of tightly packed cells. Functionally, these are defined as primitive cells by their relative resistance to 5-FU, their synergistic growth factor requirements, and their copurification with long-term reconstituting cells in vivo. ${ }^{11,16}$

${ }^{3} H$-thymidine suicide assay. This assay was performed essentially as described by Quesenberry and Stanley. ${ }^{17}$ The number of cells in S phase were detected in this assay by subjecting an aliquot of cells in culture to a high specific activity ${ }^{3} \mathrm{H}$-thymidine $(200 \mu \mathrm{Ci} /$ $\mathrm{mL}$ ) for 20 minutes at $37^{\circ} \mathrm{C}$ and determining their ability to form HPP-CFC in a double-layer agar system described above.

\section{RESULTS}

$\mathrm{Lin}^{-} \mathrm{Rho}^{\text {low }} / \mathrm{Ho}^{\text {low }}$ cells in culture with IL-3, IL-6, IL-11, and SCF evidence their first population doubling at between 36 to 40 hours, whereas subsequent population doublings occurred every 12 hours up to 100 hours (Fig 1). Details of the first cycle were determined by pulse labeling with ${ }^{3} \mathrm{H}-$ thymidine. As shown in Fig 2, replicating and nonreplicating cells exhibit a distinct pattern of staining after autoradiography and Giemsa staining of pluripotent hematopoietic stem cells. $\mathrm{Lin}^{-} \mathrm{Rho}^{\text {low }} / \mathrm{Ho}^{\text {low }}$ cells in IL-3, IL-6, IL-11, and SCF (Fig 3A) or in a 7-cytokine cocktail consisting of IL-3, IL$1 \alpha$, G-CSF, GM-CSF, SCF, CSF-1, and bFGF (Fig 3B) begin to enter $S$ phase at approximately 16 to 18 hours, and the $S$ phase peak is somewhere around 30 hours. In these experiments, about $60 \%$ of the cells were in $S$ at 30 hours of culture using a 30 -minute ${ }^{3} \mathrm{H}$-thymidine pulse label, but, when the cells were labeled over 4 hours (from 26 to 30 hours of culture), the nuclei of more than $90 \%$ of the cells were labeled with ${ }^{3} \mathrm{H}$-thymidine (data not shown), indicating that virtually all of the cells transit through the $\mathrm{S}$ phase of the first cycle during 30 hours of incubation in cytokines. Transition of all the cells incubated with cytokines through the first cycle is also indicated by a twofold increase in cell numbers (one doubling) by 36 to 40 hours (Fig 1). These data indicate that primitive $\mathrm{Lin}^{-} \mathrm{Rho}^{\text {low }} / \mathrm{Ho}^{\text {low }}$ cells, when stimulated to enter and transit cell cycle, have a $G_{1}$ phase of about 18 hours and a total cell cycle length of 36 to 40 hours. Subsequent cycles are very rapid.

Seven-factor responsive HPP-CFC represents a primitive surrogate stem cell assayed in vitro. We determined the 


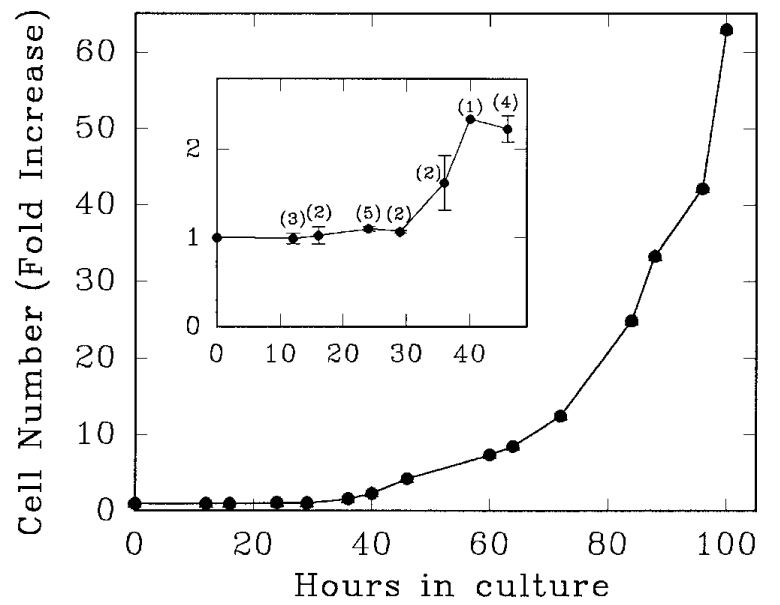

\begin{tabular}{l|l|llllll} 
Doublings: & $1^{\text {st }}$ & $2^{\text {nd }}$ & $3^{\text {rd }}$ & $4^{\text {th }}$ & $5^{\text {th }}$ & $6^{\text {th }}$ \\
Cell Cycle & 36 to 40 & 12 & 12 & 12 & 12 & 12
\end{tabular}

Fig 1. Growth rate and the doubling time of $\mathrm{Lin}^{-} \mathrm{Rho}^{\text {low }} / \mathrm{Ho}^{\text {low }}$ cells incubated in the presence of medium containing IL-3, IL-6, IL11 , and SCF. Immediately after their purification, $\mathrm{Lin}^{-} \mathrm{Rho}^{\text {low }} / \mathrm{Ho}^{\text {low }}$ cells were suspended at $10 \times 10^{3}$ cells $/ \mathrm{mL}$ in medium containing 4 cytokines and incubated at $37^{\circ} \mathrm{C}$ in a $5 \% \mathrm{CO}_{2}$ containing humidified incubator as described in the Materials and Methods. At indicated intervals, duplicate aliquots of cells from growing culture were counted using a hemocytometer. The numbers in the parentheses of the insert indicate the number of experiments from which the values for that particular time point were obtained.

number and cell cycle status of HPP-CFC in the $\mathrm{Lin}^{-}$ $\mathrm{Rho}^{\text {low }} / \mathrm{Ho}^{\text {low }}$ population both before and at 28 to 30 hours after liquid culture in IL-3, IL-6, IL-11, and SCF (Table 1). On isolation, 7-factor HPP-CFC, representing $28 \%$ of $\mathrm{Lin}^{-}$ $\mathrm{Rho}^{\text {low }} / \mathrm{Ho}^{\text {low }}$ cells, showed essentially no kill with ${ }^{3} \mathrm{H}-\mathrm{TdR}$ $(3 \% \pm 3 \%)$ and were dormant. After 28 to 30 hours of culture in IL-3, IL-6, IL-11, and SCF, cloning efficiency was
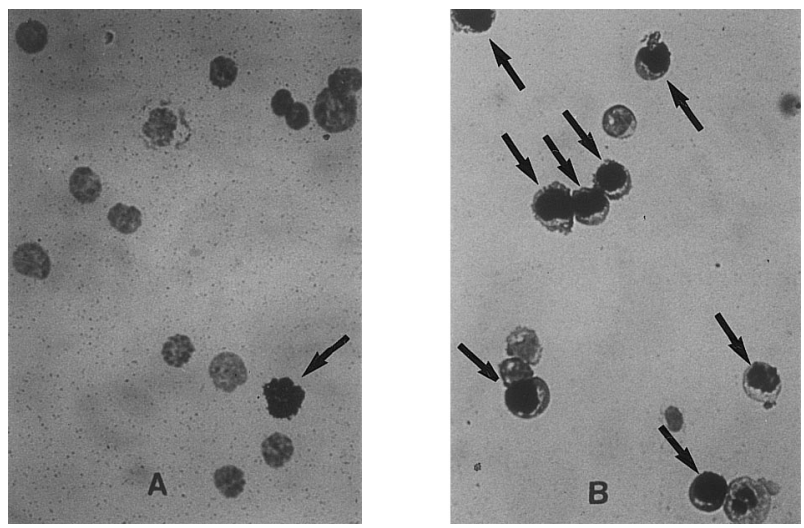

Fig 2. Representative fields of cells showing unlabeled and labeled nuclei at 0 hours $(A)$ and 30 hours $(B)$ after cytokine stimulation of $\mathrm{Lin}^{-} \mathrm{Rho}^{\text {low }} / \mathrm{Ho}^{\text {low }}$ cells. Experimental procedure for the sorting of the stem cells, their labeling with ${ }^{3} \mathrm{H}$-thymidine, autoradiography, and Giemsa staining are as described in the Materials and Methods. Cells with labeled nuclei are indicated by arrows.

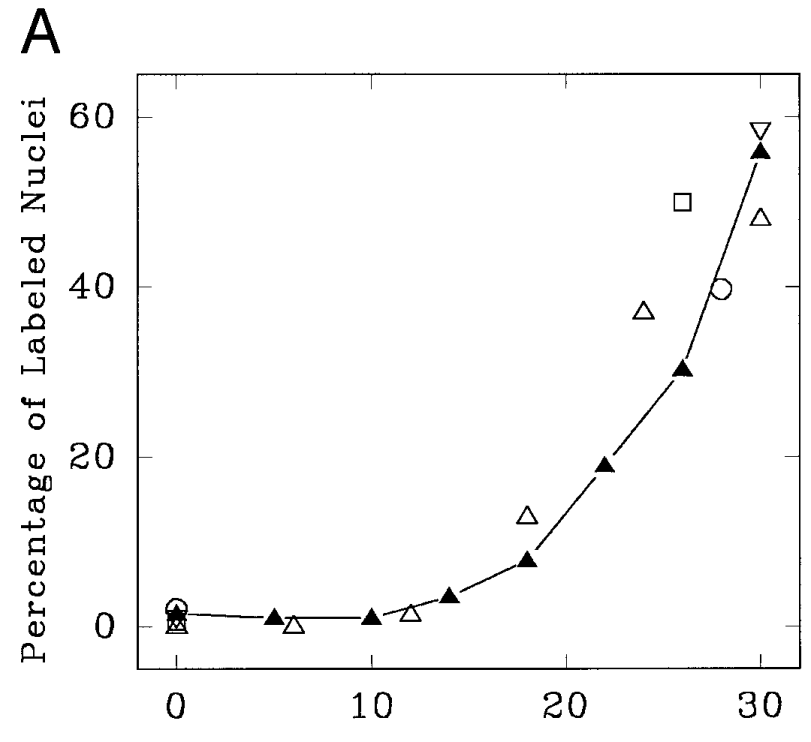

Hours of Incubation with Cytokines

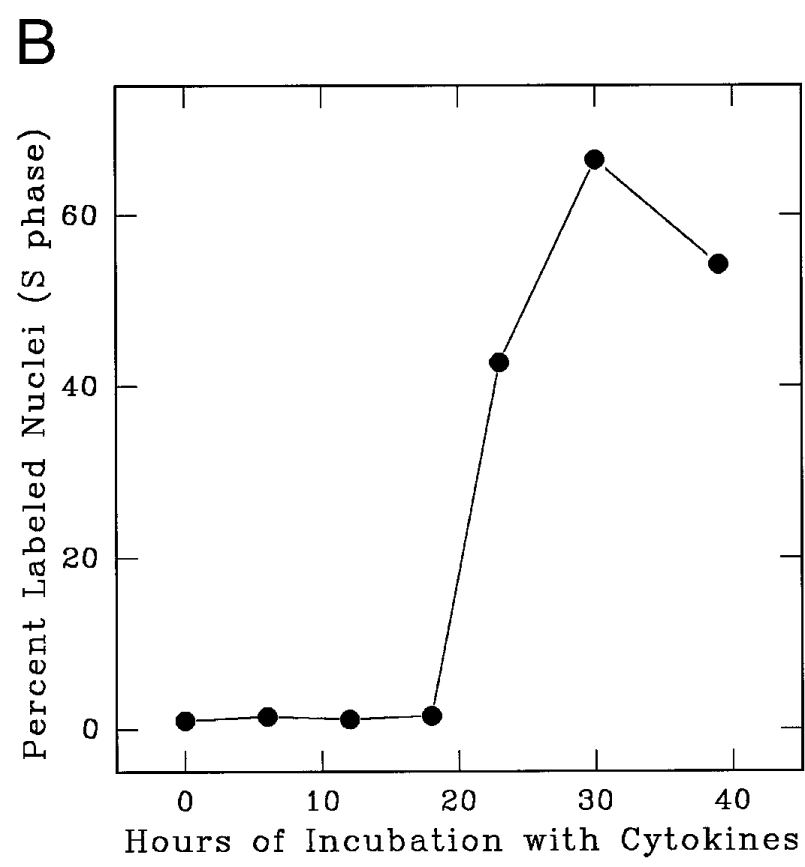

Fig 3. Progression of cytokine-stimulated $\mathrm{Lin}^{-} \mathrm{Rho}^{\text {low }} / \mathrm{Ho}^{\text {low }}$ cells through $\mathrm{G}_{0} / \mathrm{G}_{1}$ and into $\mathrm{S}$ phase. Lin ${ }^{-} \mathrm{Rho}^{\text {low }} / \mathrm{Ho}^{\text {low }}$ were incubated in medium containing a cocktail of either 4 cytokines (IL-3, IL-6, IL11, and SCF; A) or 7 cytokines (IL-3, IL-1 $\alpha$, GM-CSF, G-CSF, SCF, FGF, and CSF-1; B), and at indicated intervals duplicate aliquots of cells were analyzed for ${ }^{3} \mathrm{H}$-thymidine incorporation followed by autoradiography to assess the percentage of cells with labeled nuclei as described in the Materials and Methods. Each set of symbols in (A) represents observations from separate individual experiments.

unchanged $(31 \% \pm 7 \%)$, but the majority of HPP-CFC were in $\mathrm{S}$ phase, as shown by a $60 \% \pm 10 \%$ killing effect with ${ }^{3} \mathrm{H}-\mathrm{TdR}$ (Table 1).

In an alternate approach to studying the $\mathrm{G}_{1}$ period of the cells in second cycle, $\mathrm{Lin}^{-} \mathrm{Rho}^{\text {low }} / \mathrm{Ho}^{\text {low }}$ cells stimulated for 
Table 1. Cell Cycle Status of $\mathrm{Lin}^{-} \mathrm{Rho}^{\mathrm{low}} / \mathrm{Ho}^{\text {low }}$-Derived HPP-CFC Cultured in Cytokines

\begin{tabular}{lcc}
\hline Time in Culture & HPP-CFC/100 Cells ${ }^{*}$ & \% Killed by ${ }^{3} \mathrm{H}-\mathrm{TdR} \dagger$ \\
\hline $0 \mathrm{~h}$ & $28 \pm 13$ & $3 \pm 3$ \\
$28-30 \mathrm{~h}$ & $31 \pm 7$ & $60 \pm 10 \ddagger$ \\
\hline
\end{tabular}

* Seven-factor-responsive HPP-CFC per 100 cells from initially isolated $\mathrm{Lin}^{-} \mathrm{Rho}^{\text {low }} \mathrm{Ho}^{\text {low }}$ cells and after 28 to 30 hours in culture with IL-3, IL-11, IL-6, and SCF (see the Materials and Methods).

† Cell cycle status of HPP-CFC as determined by ${ }^{3} \mathrm{H}-\mathrm{TdR}$ suicide. These data are from four separate experiments with 4 to 10 culture plates per group in each experiment.

‡ Significantly different from 0 hours value (Wilcoxon rank-sum test; $P=.0209$ ).

36 hours with IL-3, IL-6, IL-11, and SCF were subjected to isoleucine-deprivation to arrest them in early- $\mathrm{G}_{1}$ of subsequent cycle. We observed that isoleucine-deprivation for 26 to 30 hours effectively limited stem cells completing first $\mathrm{S}$ phase from progressing through the subsequent $\mathrm{G}_{1}$ and entering into the second S phase (Fig 4). During this entire period, the cell number doubled once, indicating their arrest immediately after the first cycle, and their viability remained unchanged as determined by their ability to exclude TrypanBlue. When isoleucine-deprived cells were refed with complete medium, they immediately entered into $\mathrm{S}$ phase (Fig 5), exhibiting a short (1 to 2 hours) $G_{1}$ for cells that have completed first cycle.

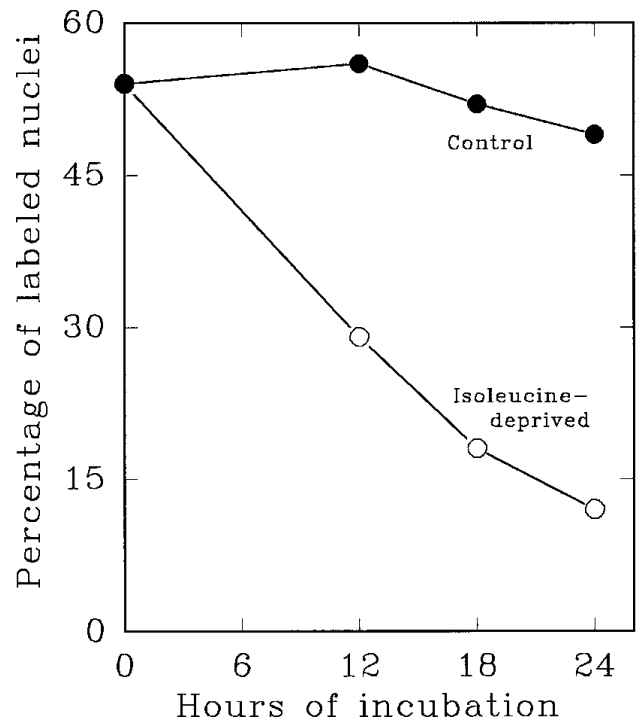

Fig 4. Cytokine-stimulated $\mathrm{Lin}^{-} \mathrm{Rho}^{\text {low }} / \mathrm{Ho}^{\text {low }}$ cells in first $\mathrm{S}$ phase are blocked in subsequent $\mathbf{G}_{0} / \mathbf{G}_{1}$ phase by isoleucine-deprivation. $\mathrm{Lin}^{-} \mathrm{Rho}^{\text {low }} / \mathrm{Ho}^{\text {low }}$ cells were incubated in medium containing a cocktail of 4 cytokines (IL-3, IL-6, IL-11, and SCF) at $37^{\circ} \mathrm{C}$ in a humidified incubator with $5 \% \mathrm{CO}_{2}$. Thirty hours later, when about $60 \%$ of the cells are in $\mathbf{S}$ phase, the total culture was divided into two groups of equal cell number. One group of the cells was maintained in the same media as described above and the other group of cells was subjected to isoleucine-deprivation as described in the Materials and Methods. At indicated intervals, $200-\mu \mathrm{L}$ aliquots of cells from each group were analyzed for the percentage of labeled nuclei as described in the Materials and Methods.

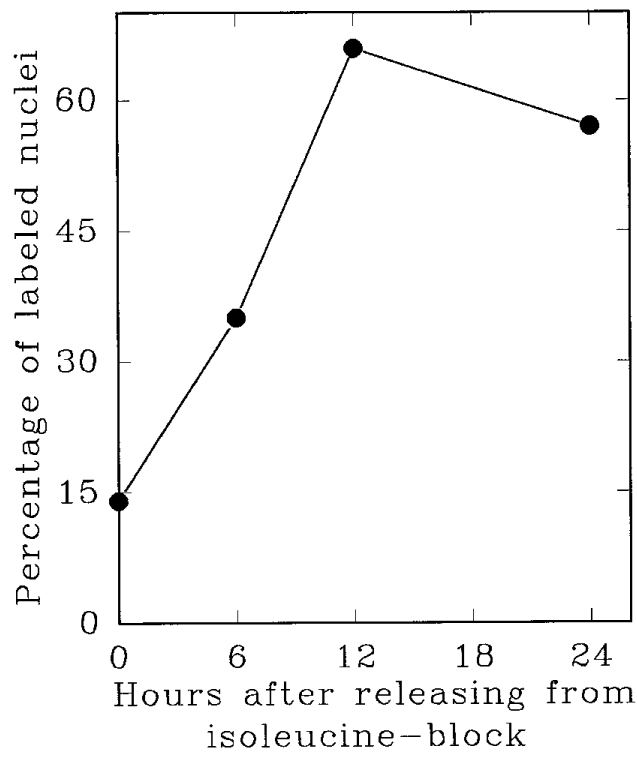

Fig 5. S phase-enriched $\mathrm{Lin}^{-} \mathrm{Rho}^{\text {low }} / \mathrm{Ho}^{\text {low }}$ cells arrested in subsequent $G_{0} / G_{1}$ phase by isoleucine-deprivation re-enter proliferative cycle after the release from isoleucine-block. Thirty hours after cytokine stimulation, $\mathrm{Lin}^{-} \mathrm{Rho}^{\text {low }} / \mathrm{Ho}^{\text {low }}$ cells were subjected to isoleucinedeprivation for $\mathbf{3 6}$ hours as described in the Materials and Methods. The cells were then released from isoleucine-block and at indicated intervals duplicate aliquots of cells were labeled with ${ }^{3} \mathrm{H}$-thymidine and processed for autoradiography to assess the percentage of cells with labeled nuclei as described in the Materials and Methods.

We also evaluated an alternate population of purified hematopoietic stem cells, $\mathrm{Lin}^{-} / \mathrm{Sca}^{+}$cells, stimulated by SCF, SCF plus IL-3, or a 7-cytokine cocktail (Fig 6). Here, approximately $10 \%$ of the purified cells were labeled with ${ }^{3} \mathrm{H}-$ thymidine at time 0 in culture, indicating a less quiescent population than that represented by $\mathrm{Lin}^{-} \mathrm{Rho}^{\text {low }} / \mathrm{Ho}^{\text {low }}$. The

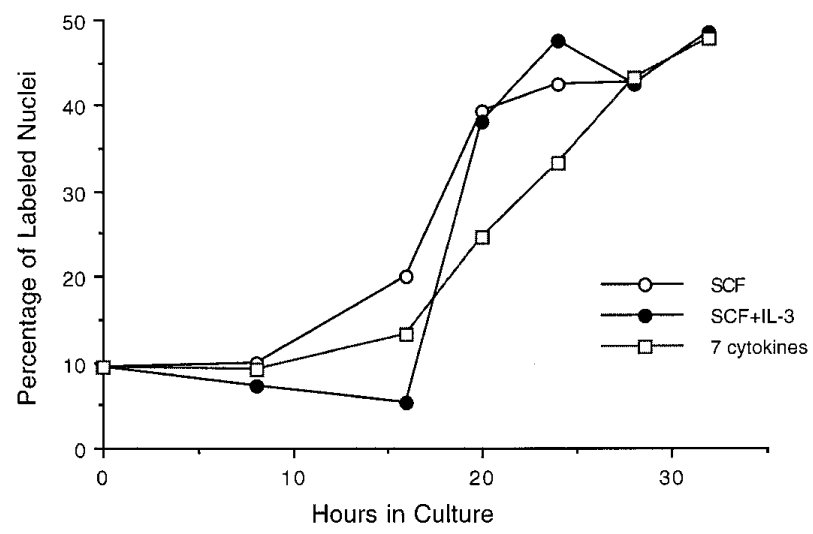

Fig 6. Progression of cytokine-stimulated $\mathrm{Lin}^{-} / \mathrm{Sca}^{+}$cells through $\mathrm{G}_{1}$ and into $\mathrm{S}$ phase of cell cycle. $\mathrm{Lin}^{-} / \mathrm{Sca}^{+}$cells were incubated in medium containing SCF alone, SCF plus IL-3, or a cocktail of 7 cytokines (IL-3, IL-1 $\alpha$, GM-CSF, G-CSF, SCF, FGF, and CSF-1), and at indicated intervals duplicate aliquots of cells from each group were analyzed for ${ }^{3} \mathrm{H}$-thymidine incorporation followed by autoradiography to assess the percentage of cells with labeled nuclei as described in the Materials and Methods. 


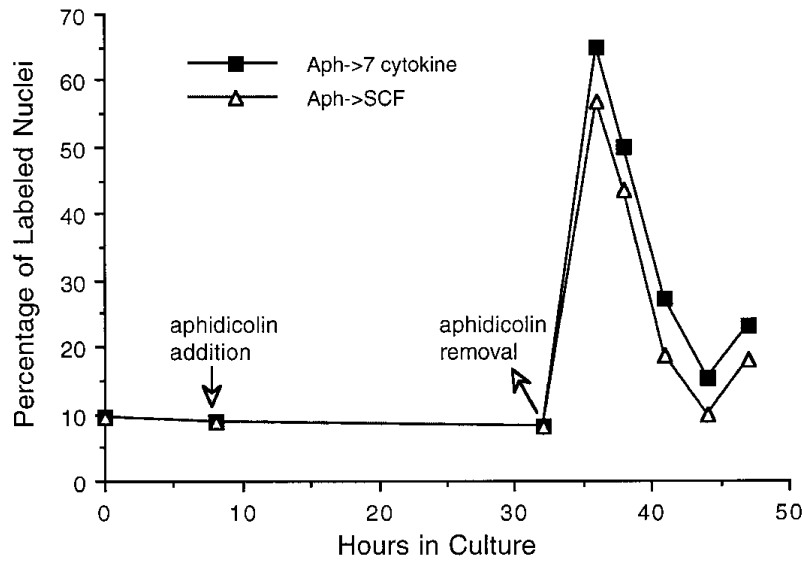

Fig 7. Progression of $\mathrm{Lin}^{-} / \mathrm{Sca}^{+}$cells synchronized at $\mathrm{G}_{1} / \mathrm{S}$ boundary by aphidicolin treatment through $\mathrm{S}$ phase. Freshly isolated $\mathrm{Lin}^{-} /$ $\mathrm{Sca}^{+}$cells were incubated in medium containing 7 cytokines. From 8 to 32 hours thereafter, cells were treated with aphidicolin as indicated by the arrows. Cells were then washed once with cytokine-free medium and incubated with medium containing either 7 cytokines or SCF alone. At indicated intervals, duplicate aliquots of cells from each group were analyzed for ${ }^{3} \mathrm{H}$-thymidine incorporation followed by autoradiography to assess the percentage of cells with labeled nuclei as described in the Materials and Methods.

general profile and the temporal order of their progression through $G_{0} / G_{1}$ and into $S$ phase is found to be essentially similar to that seen with $\mathrm{Lin}^{-} \mathrm{Rho}{ }^{\text {low }} / \mathrm{Ho}^{\text {low }}$ cells. Furthermore, the lag period of 16 to 18 hours and the fraction of cells entering into $S$ phase at 28 to 30 hours observed in the presence of SCF alone remained unchanged when SCF was combined with IL-3 (2-cytokine combination) or with IL3, GM-CSF, IL-1 $\alpha$, bFGF, CSF-1, and G-CSF (7-cytokine combination). Thus, SCF alone in the presence of $5 \% \mathrm{HI}-$ FCS is as effective as multiple cytokine combinations for inducing the progression of $\mathrm{Lin}^{-} / \mathrm{Sca}^{+}$cells from a quiescent state into proliferative cycle and into $\mathrm{S}$ phase. However, supplementing SCF containing media with HI-FCS was found to be essential for cell viability, because, in its absence, a progressive cell death was observed during the first 24-hour incubation period (data not shown). Similarly, HIFCS alone in the medium, without SCF, was not sufficient for the proliferative stimulation of the cells (data not shown). Thus, these cells require a minimum of serum factors and SCF for their entry into and subsequent progression through the cell cycle.

As can be seen in Fig 6, 50\% to $60 \%$ of $\mathrm{Lin}^{-} / \mathrm{Sca}^{+}$cells entered synchronously into $\mathrm{S}$ phase by 30 hours after cytokine stimulation. To achieve more synchronous entry of cells into first $\mathrm{S}$ phase and to establish procedures that allow the maintenance of stem cell synchrony as they complete first $S$ phase and enter into subsequent cycle, we examined the ability of aphidicolin, an inhibitor of DNA polymerase $\alpha,{ }^{18}$ to reversibly block cytokine stimulated $\mathrm{Lin}^{-} / \mathrm{Sca}^{+}$cells at $\mathrm{G}_{1} / \mathrm{S}$ boundary. As shown in Fig $7, \mathrm{Lin}^{-} / \mathrm{Sca}^{+}$cells exposed to a combination of 7 cytokines were limited from entering into $S$ phase after aphidicolin treatment from 8 to 32 hours after cytokine stimulation. This is in contrast to more than
$50 \%$ of the cells being in S phase in the absence of aphidicolin during the same incubation period (Fig 6). When the cells were released from aphidicolin block, they entered into $S$ phase without any detectable lag period, indicating their arrest at $G_{1} / S$ boundary or in early-S phase in response to aphidicolin. These cells retained a tight synchrony as they completed $\mathrm{S}$ phase and traversed through the subsequent phases of cell cycle (Fig 7). Furthermore, as in cytokinestimulated cells, SCF alone was as effective as the 7-cytokine cocktail in allowing the progression of aphidicolin-synchronized $\mathrm{Lin}^{-} / \mathrm{Sca}^{+}$cells through $\mathrm{S}$ phase.

\section{DISCUSSION}

The present data indicated that highly purified $\mathrm{Lin}^{-}$ $\mathrm{Rho}^{\text {low }} / \mathrm{Ho}^{\text {low }}$ murine lymphohematopoietic stem cells are quiescent at isolation, but with exposure to a cytokine combination of IL-3, IL-6, IL-11, and SCF, enters and progresses through cell cycle with an initial cycle length of 36 to 40 hours. Subsequent cycles appear to be about 12 hours in length. These data were based on cell numbers and ${ }^{3} \mathrm{H}$-thymidine labeling and their functional significance was confirmed by induction of quiescent 7-factor HPP-CFC into S phase. Given the length of $S$ phase, these data indicate that essentially all cells traversed $S$ phase. In other studies using whole unseparated marrow exposed to the same cytokine combinations, we have shown that, at 48 hours of culture, the cells show very poor long-term engraftment in either irradiated or normal hosts, but more recent studies indicate that this engraftment defect is reversible over time, although it is virtually impossible to rule out some degree of differentiation within the stem progenitor classes in these experiments. The data cited above indicate that the population retains stem cell-like properties through multiple cell cycle transits. A detailed analysis of the first cell cycle transit indicates a $G_{1}$ phase of about 18 hours and a total cycle length of 36 to 40 hours. Given the relative fixed minimum of 7 to 8 hours for S, 2 hours for $G_{2}$, and 1 hour for $M$, the $G_{1}$ in the subsequent cycle must be very short, in the range of 1 to 2 hours. The isoleucine deprivation studies (see below) add further evidence for a very short $G_{1}$ in cytokine-stimulated Lin $^{-}$ $\mathrm{Rho}^{\text {low }} / \mathrm{Ho}^{\text {low }}$ cell cycles after the first cell cycle transit.

Dogma suggests that $\mathrm{Lin}^{-} \mathrm{Rho}^{\text {low }} / \mathrm{Ho}^{\text {low }}$ cells are dormant and not easily stimulated to divide, but our data suggest that all of these cells are easily induced to enter cell cycle. Studies by Hendrikx et $\mathrm{al}^{19}$ on transplantation of highly purified murine marrow stem cells and using PKMH-26 fluorescence labeling indicate that the majority of engrafted cells have divided over a 24-hour period after intravenous infusion. These studies suggest cycle times for primitive stem cells stimulated from dormancy of 24 to 48 hours. This is to be contrasted by recent studies by Bradford et al, ${ }^{1}$ using prolonged continuous labeling with BrdU, indicating that the average turnover time of $\mathrm{Lin}^{-} \mathrm{Rho}^{\text {low }} / \mathrm{Ho}^{\text {low }}$ cells in vivo was 4.3 weeks with a time to $50 \%$ cycle of 2.75 weeks. These investigators also reported that, over a 12 -week labeling period, $89 \%$ of $\mathrm{Lin}^{-} \mathrm{Rho}^{\text {low }} / \mathrm{Ho}^{\text {low }}$ cells incorporated BrdU. This is, of course, a steady-state situation, but these data do not distinguish between a prolonged cell cycle for most cells or 
an intermittent entrance of dormant cells into cell cycle with a shorter cycle length.

Studies of 7-factor-responsive HPP-CFC indicate that this surrogate stem cell was dormant in freshly isolated $\mathrm{Lin}^{-}$ $\mathrm{Rho}^{\text {low }} / \mathrm{Ho}^{\text {low }}$ cells but was clearly transiting cell cycle by 28 to 30 hours of culture in IL-3, IL-6, IL-11, and SCF. The percentage of HPP-CFC in cycle (Table 1) closely approximated the percentage of $\mathrm{Lin}^{-} \mathrm{Rho}^{\text {low }} / \mathrm{Ho}^{\text {low }}$ cells that labeled with ${ }^{3} \mathrm{H}-\mathrm{TdR}$ (Fig 3).

As shown in Fig 3, cytokine-stimulated cells entered synchronously into $\mathrm{S}$ phase, with $55 \%$ to $60 \%$ of them in $\mathrm{S}$ phase at 30 hours. During 90 to 100 hours of incubation with cytokines after the first cycle, about $60 \%$ of cells continued to be in $\mathrm{S}$ phase as determined by autoradiography analysis of the cells pulse-labeled with ${ }^{3} \mathrm{H}$-thymidine at 12 - to 14 hour intervals (Fig 4, data not shown). This indicates either that a partial synchrony of the cells persisted as they traversed through the subsequent cycles with maximum number of cells in S phase at every 12 to 14 hours examined or that the cells after first cycle grew exponentially, with $60 \%$ of the cells in $\mathrm{S}$ phase through the remainder of the proliferative period. The latter possibility implies that the $\mathrm{S}$ phase of exponentially growing cells constitutes greater than $60 \%$ of total cell cycle time during each division after the first cycle. The doubling time of 12 hours with a $\mathrm{S}$ period of 7 to 8 hours after the first division observed in the present studies (Fig 1) is consistent with such a possibility.

Alternate populations representing $\mathrm{Lin}^{-} / \mathrm{Sca}^{+}$stem cells stimulated with SCF alone, SCF plus IL-3, or a cocktail of 7 cytokines also exhibited cell cycle kinetics similar to those observed with $\mathrm{Lin}^{-} \mathrm{Rho}^{\text {low }} / \mathrm{Ho}^{\text {low }}$ cells. However, unlike $\mathrm{Lin}^{-}$ $\mathrm{Rho}^{\text {low }} / \mathrm{Ho}^{\text {low }}$ cells, $\mathrm{Lin}^{-} / \mathrm{Sca}^{+}$cells were heterogeneous, with $10 \%$ to $15 \%$ of them in $\mathrm{S}$ phase immediately after their sorting (Fig 6). Their entry into, and progression through, the first cycle essentially remained the same whether they were stimulated with SCF alone or with 7 cytokines. A partial synchrony of these cells was maintained as they traversed through $\mathrm{G}_{1}$ into $S$ phase (Fig 6).

To enrich PHSCs in first $\mathrm{S}$ and to acquire the synchrony that can be sustained as the cells transit through the first $G_{2}$ and $\mathrm{M}$ phases, we tested the ability of aphidicolin to reversibly block $\mathrm{Lin}^{-} / \mathrm{Sca}^{+}$cells at their first $\mathrm{G}_{1} / \mathrm{S}$ boundary. Selective antimetabolites, including aphidicolin (inhibitor of DNA polymerase $\alpha$ ), hydroxyurea (inhibitor of ribonucleotide reductase), and methotrexate (inhibitor of dihydrofolate reductase), that inhibit DNA replication and DNA precursor synthesis have been used to synchronize a variety of mammalian cells at $\mathrm{G}_{1} / \mathrm{S}$ boundary. ${ }^{20,21}$ Our observations show that $\mathrm{Lin}^{-} / \mathrm{Sca}^{+}$cells, like other cell systems, respond to a secondary synchronization at $\mathrm{G}_{1} / \mathrm{S}$ boundary after aphidicolin treatment (Fig 7). Considering its selective inhibitory effect on DNA polymerase $\alpha^{17}$ and its ineffectiveness in altering $\mathrm{G}_{1}$ associated erythroid differentiation of MELC cells in vitro, ${ }^{22}$ aphidicolin may not show secondary effects that are independent of cell cycle status that it induces.

We tested both the serum-deprivation and the isoleucinedeprivation methods that are commonly used to achieve $\mathrm{G}_{0} / \mathrm{G}_{1}$ phase arrest of a variety of cells, including hematopoietic progenitor cells, ${ }^{23-25}$ for their ability to block PHSCs completing first $\mathrm{S}$ phase from entering into second proliferative cycle. Whereas serum (HI-FCS)-deprived PHSCs experienced a progressive death with time (data not shown), isoleucine-deprivation reversibly blocked them in a nonproliferative state after first division (see Figs 4 and 5). As compared with PHSCs in their first cycle, those released from isoleucine-block entered into $\mathrm{S}$ phase with a shorter lag $\left(\mathrm{G}_{1}\right)$ period.

Thus, these studies describe essential cytokine and serum conditions required for the synchronous progression of purified PHSCs from their initial $G_{0} / G_{1}$ phase into $S$ phase and identify for the first time two specific approaches to synchronize PHSCs at $\mathrm{G}_{1} / \mathrm{S}$ boundary of their first cycle (aphidicolin-induced synchrony) and at $\mathrm{G}_{0} / \mathrm{G}_{1}$ phase of their second cycle (isoleucine-deprivation-induced synchronization of the cells completing first $\mathrm{S}$ phase). They also show a relatively long cycle time from dormancy of primitive $\mathrm{Lin}^{-} \mathrm{Rho}^{\text {low }}$ $\mathrm{Ho}^{\text {low }}$ hematopoietic stem cells with a subsequent rapid cycle transit and short $G_{1}$. Given the apparent fluctuation of engraftment with cell cycle status, these results have important implications for clinical marrow transplantation and gene therapy strategies.

\section{ACKNOWLEDGMENT}

The authors are thankful to Christina Grimaldi, Judy Reilly, and Dr Ruud Hulspas for their help in sorting bone marrow cells.

\section{REFERENCES}

1. Bradford GB, Williams B, Rossi R, Bertoncello I: Quiescence, cycling and turnover in the primitive hematopoietic stem cell compartment. Exp Hematol 25:445, 1997

2. Karlsson S: Treatment of genetic defects in hematopoietic cell function by gene transfer. Blood 78:2481, 1991

3. Mulligan RC: The basic science of gene therapy. Science 260:926, 1993

4. Miller AD: Human gene therapy comes of age. Nature 357:455, 1992

5. Szilvassy SJ, Cory S: Efficient retroviral gene transfer to purified long-term repopulating hematopoietic cells. Blood 84:74, 1994

6. Bodine DM, Karisson S, Nienhuis AW: Combination of interleukin-3 and 6 preserves stem cell function in culture and enhances retrovirus-mediated gene transfer into hematopoietic stem cells. Proc Natl Acad Sci USA 86:8897, 1989

7. Carter RF, Abrams-Ogg ACG, Dick JE, Kruth SA, Valli VE, Kamel-Reid S, Dube ID: Autologous transplantation of canine longterm marrow culture cells genetically marked by retroviral vector. Blood 79:356, 1992

8. Peters SO, Kittler EL, Ramshaw HS, Quesenberry PJ: Murine marrow cells expanded in culture with IL-3, IL-6, IL-11, and SCF acquire an engraftment defect in normal hosts. Exp Hematol 23:461, 1995

9. Peters SO, Kittler EL, Ramshaw HS, Quesenberry PJ: Ex vivo expansion of murine marrow cells with interleukin-3, interleukin-6, interleukin-11, and stem cell factor leads to impaired engraftment in irradiated hosts. Blood 87:30, 1996

10. Ramshaw HS, Rao SS, Crittenden RB, Peters SO, Weier HU, Quesenberry PJ: Engraftment of bone marrow cells into normal unprepared hosts: Effects of 5-fluorouracil and cell cycle status. Blood 86:924, 1995

11. McNiece IK, Bertoncello I, Kriegler AB, Quesenberry PJ: Colony-forming cells with high proliferative potential (HPP-CFC). Int J Cell Cloning 8:146, 1990

12. Flemming W, Alpern EJ, Uchida N, Ikuta K, Spangrude GJ, 
Weissman IL: Functional heterogeneity is associated with cell cycle status of murine hematopoietic stem cells. J Cell Biol 122:897, 1993

13. Wolf NS, Kone A, Priestly GV, Bartlmez SH: In-vivo and in-vitro characterization of long-term repopulating primitive hematopoietic cells isolated by sequential Hoechst 33342-rhodamine 123 FACS selection. Exp Hematol 21:614, 1993

14. Reddy GPV: Compartmentation of deoxypyrimidine nucleotides for nuclear DNA replication in S phase mammalian cells. J Mol Recog 2:75, 1989

15. Bartelmez SH, Bradley TR, Bertoncello I, Mochizuki DY, Tushinski RJ, Stanley ER, Hapel AJ, Young IG, Kriegler AB, Hodgson GS: Interleukin 1 plus interleukin 3 plus colony-stimulating factor 1 are essential for clonal proliferation of primitive myeloid bone marrow cells. Exp Hematol 17:240, 1989

16. Bertoncello I: Status of high proliferative potential colonyforming cells in the hematopoietic stem cell hierarchy. Curr Top Microbiol Immunol 177:83, 1992

17. Quesenberry PJ, Stanley K: A statistical analysis of murine stem cell suicide techniques. Blood 56:1000, 1980

18. Huberman JA: New views of the biochemistry of eukaryotic DNA replication revealed by aphidicolin, an unusual inhibitor of DNA polymerase alpha. Cell 23:647, 1981
19. Hendrikx PJ, Martens ACM, Hagenbeek A, Keij JF, Visser WM: Homing of fluorescently labeled murine hematopoietic stem cells. Exp Hematol 24:129, 1996

20. Lalande M: A reversible arrest point in the late G1 phase of the mammalian cell cycle. Exp Cell Res 186:332, 1990

21. Reddy GPV: Catalytic function of thymidylate synthase is confined to $\mathrm{S}$ phase due to its association with replitase. Biochem Biophys Res Commun 109:908, 1982

22. Kiyokawa H, Richon VM, Venta-perez G, Rifkind RA, Marks PA: Hexamethylenebisacetamide-induced erythroleukemia cell differentiation involves modulation of events required for cell cycle progression through G1. Proc Nat Acad Sci USA 90:6746, 1993

23. Rossow PW, Riddle VGH, Pardee AB: Synthesis of labile, serum-dependent protein in early G1 controls animal cell growth. Proc Natl Acad Sci USA 76:4446, 1979

24. Tobey RA: Production and characterization of mammalian cells reversibly arrested in G1 by growth in isoleucine-deficient medium. Methods Cell Biol 6:67, 1973

25. Reddy GPV, Reed WC, Deacon DH, Quesenberry PJ: Growth factor-dependent proliferative stimulation of hematopoietic cells is associated with the modulation of cytoplasmic and nuclear $68-\mathrm{Kd}$ calmodulin-binding protein. Blood 79:1946, 1992 